\title{
Introduction to the Special Issue on the Psychodynamic Diagnostic Manual, 2nd Edition (PDM-2): The PDM: Yesterday, Today, Tomorrow
}

\author{
Vittorio Lingiardi, MD \\ Sapienza University of Rome
}

\author{
Nancy McWilliams, PhD \\ Rutgers University
}

\begin{abstract}
In this introductory essay, we review the development of the second edition of the Psychodynamic Diagnostic Manual. We place the first edition in historical context and note the main responses and critiques of professional colleagues to its publication. We then outline the developing process of this second, comprehensively revised edition. Finally, we preview the contributions to this Special Issue. Overall, we emphasize the Psychodynamic Diagnostic Manual's innovative diagnostic framework, designed to assess the depth as well as the surface of patients' emotional, cognitive, interpersonal, and social patterns and to foster in the field an integration between nomothetic understanding and the idiographic knowledge useful for case formulation and treatment planning.
\end{abstract}

Keywords: Psychodynamic Diagnostic Manual, diagnosis, clinical utility

\begin{abstract}
There is, however, a pitfall here. Our diagnoses are very often made only after the event. They resemble the Scottish king's test for identifying witches that I read about in Victor Hugo. This king declared that he was in possession of an infallible method of recognizing a witch. He had the women stewed in a cauldron of boiling water and then tasted the broth. Afterward he was able to say: "That was a witch," or "No, that was not one." It is the same with us, except that we are the sufferers.

- Sigmund Freud, New Introductory Lectures on Psycho-Analysis, standard edition (Freud, 1933, p. 155)
\end{abstract}

In 2006, when the first edition of the Psychodynamic Diagnostic Manual (PDM-1) was published, psychiatric nosology was going through a period of critical change. The latest versions of the Diagnostic and Statistical Manual of Mental Disorders (DSM) and the International Classification of Diseases (ICD) seemed not to meet the needs of clinicians, who sought to diagnose their individual patients in terms of their full range of mental functioning, not only via present versus absent symptomatic criteria. Focusing on the whole functioning of an individual, the first edition aspired

Editor's Note. This is an introduction to the special issue "The PDM-2 and Clinical and Research Issues in Psychodynamic Diagnosis." Please see the Table of Contents here: http://psycnet.apa.org/journals/pap/35/3.-CC

Vittorio Lingiardi, MD, Department of Dynamic and Clinical Psychology, Sapienza University of Rome; Nancy McWilliams, PhD, Graduate School of Applied and Professional Psychology, Rutgers University.

Vittorio Lingiardi and Nancy McWilliams are coeditors of the PDM-2, but they earn no royalties from the publication and have no other financial interest in the manual.

Correspondence concerning this article should be addressed to Vittorio Lingiardi, MD, Department of Dynamic and Clinical Psychology, Faculty of Medicine and Psychology, Sapienza University of Rome, Via degli Apuli, 1, 00185 Rome, Italy. E-mail: vittorio.lingiardi@uniroma1.it to be truer to the original Greek meaning of diagnosis as a thorough knowing or knowing through-a taxonomy of people rather than a taxonomy of disorders. We soon realized that this approach, systematic and at the same time clinically articulated, was filling a gap. There was no other diagnostic manual with those features, and the need for them was great among both clinicians and clinical researchers.

\section{Yesterday}

Given the success of the first edition (in 2009, Paul Stepansky [Stepansky (2009)] called it a stunning success) and in response to feedback about its strengths and weaknesses, we gathered a large group of consultants and collaborators and got to work revising the original PDM to enhance its empirical rigor and clinical utility. We felt it was crucial for the international community to have a diagnostic manual that integrates the clinical knowledge of psychoanalysts with the expertise of empirical researchers and scholars in the areas of attachment, mentalization, child development, personality, and psychotherapy in dialogue with cognitive psychology and neuroscience.

The first edition of the Psychodynamic Diagnostic Manual was intended to be a best-effort, provisional document, a manual that its authors hoped would be improved by the critiques of colleagues once it reached its natural audience of interested clinicians and researchers. Stanley Greenspan, who first envisioned the project, wanted to keep the cost of the book low enough for students to afford it; accordingly, he chose to publish it as needed via the in-house resources of his organization, the Interdisciplinary Council on Developmental and Learning Disorders (ICDL). He was busy soliciting and receiving feedback about PDM-1 when he fell ill and died within four years of its publication.

Fortunately, his wife, Nancy Greenspan, who has been unfailingly supportive of the second edition of the PDM, protected the funds that came in each time a copy was ordered from the ICDL. The Steering Committee of PDM-1 had determined that 
all such income would be used for psychotherapeutically oriented research and teaching - a decision that remains in force for the Psychodynamic Diagnostic Manual, 2nd Edition (PDM2). After Dr. Greenspan's death and in light of the advanced age of most people on the PDM-1 Steering Committee, it looked for a while as if the endeavor would die. A sufficient number of professionals proved eager to move forward, however, that Vittorio Lingiardi was able to resuscitate the project from Sapienza University in Rome and start planning a second edition. His first step was to recruit as his associate the only surviving editor of PDM-1, Nancy McWilliams.

Despite the fact that such a decision would make PDM-2 more expensive than PDM-1, we decided to approach a respected commercial publisher with the project so that it would be professionally copyedited and marketed. Because the PDM-1 was privately published by the ICDL, there were many communities that had never encountered it. (On the other hand, there were some places where it was well known; in New Zealand, e.g., treatment can be reimbursed by the government via a diagnosis from either the DSM, the ICD, or the PDM). We were fortunate that Guilford Publications was strongly interested and that Jim Nageotte became our editor.

There were several important critical reactions to PDM-1 that came to us despite the loss of Dr. Greenspan's role in fielding such critiques. Those that were widely shared or seemed to us to have special merit led us to make significant changes in the manual. The most important were the addition of a psychotic level of personality organization, the expansion of the positive mental capacities described in the M Axis, the separation of the Child and Adolescent sections, the addition of a section on geriatric issues, the addition of specific clinician-friendly assessment tools, a more extensive discussion of the subjective experience of symptoms and the countertransference reactions of clinicians, and increased comparisons and contrasts between the PDM-2 and the ICD and DSM systems of classification. In several places, we gave more attention to the late Sidney Blatt's work on polarities of experience.

In addition, we wanted to make the PDM-2 a more extensively international project than the PDM-1 had been. To that end, we recruited contributors and advisers from a wider base than the first edition's. Our final list, although heavy on Italian and North American scholars, includes contributors from Argentina, Australia, Austria, Belgium, Canada, France, Germany, Greece, Iran, Israel, Italy, New Zealand, Norway, Sweden, Switzerland, Turkey, and the United Kingdom. All the PDM-1 sponsoring organizations (the American Psychoanalytic Association, the International Psychoanalytical Association, the Division of Psychoanalysis of the American Psychological Association, the American Academy of Psychoanalysis and Dynamic Psychiatry, and what is now the American Association for Psychoanalysis in Clinical Social Work) confirmed their willingness to endorse the PDM-2 project. We were able to double the number of sponsoring organizations with endorsements from the Association Européenne de Psychopathologie de l'Enfant et de l'Adolescent, the Confederation of Independent Psychoanalytic Societies, the International Association for Relational Psychoanalysis and Psychotherapy, the International Society of Adolescent Psychiatry and Psychology, and the Italian Group for the Advancement of Psychodynamic Diagnosis.

We appointed an Honorary Scientific Committee to advise us. We agreed that in the PDM-2, the empirical citations supporting the manual's approach should be referenced throughout the article rather than, as in PDM-1, via separate articles by leading psychoanalytic researchers. Of possible interest to readers of this journal, we were inclined to make one change that did not pan out: Because we were hearing from nonpsychoanalytically identified clinicians (professionals from cognitive-behavioral, emotion-focused, family systems, humanistic, and biological orientations) that the PDM-1 had been comprehensible and valuable to them, we considered renaming the book either the Practitioner's Diagnostic Manual or the Psychological Diagnostic Manual, thus emphasizing its effort to synthesize knowledge across orientations and disciplines. For reasons related to marketing an established brand, Guilford Publications opposed this idea.

The PDM-2 project would never have been achieved without Dr. Greenspan's original vision; we find ourselves thinking of him as our Magellan. We want to acknowledge as well the late Robert Wallerstein, who acted as our primary consultant and Honorary Chair until his death in December 2014. One of his last letters to us restated his hopes for this edition and his wish that the PDM "will have an enduring life."

\section{Today}

We believe that the diagnostic process has no simple, easily applied formula (Lingiardi \& McWilliams, 2015). In his General Psychopathology, Karl Jaspers (Jaspers, 1913) claims that "every diagnostic schema must remain a tiresome problem for the scientist" (Alle Diagnosenschemata müssen für den Forscher eine Qual Bleiben). In the original quote, the German word qual is used where "tiresome" has been translated here; Qual literally means torment, and, in fact, we think that for researchers and clinicians, diagnosis should be, if not a torment, at list a tension. There is always a tension between the need to associate a patient with a general category and, at the same time, to specify the person's unique qualities — "the impossible science of the unique being," in the words of Roland Barthes (Barthes, 1980, p. 71). A useful diagnostic manual should maintain a healthy tension between the goals of capturing the complexity of clinical phenomena (functional understanding) and developing criteria that can be reliably judged and used in research (descriptive understanding).

The PDM-2 offers a diagnostic framework designed to examine the depth as well as the surface of emotional, cognitive, interpersonal, and social patterns of patients. It fosters integration between nomothetic understanding and idiographic knowledge useful for case formulation and treatment planning, emphasizing individual variations as well as commonalities. It tries to revive Adolf Meyer's seminal vision of a biopsychosocial psychiatry by bringing attention to the importance of diagnosis across the life cycle.

The PDM-2 is divided into age groups (adults, adolescents, children, infancy and early childhood, later life) and uses a multidimensional approach to capture the intricacies of the patient's overall functioning and ways of engaging in the therapeutic process. Each age range is characterized by three axes along which the clinician may conceptualize a patient: $\mathrm{P}$ Axis (personality syndromes), M Axis (profile of mental functioning), and $\mathrm{S}$ Axis (symptom patterns: The subjective experience). The multiaxial approach for the Infancy and Early Childhood section differs from the others because of the unique qualities of the first 3 years of life. 
We are hoping that the PDM-2 can clear up some common misconceptions about diagnosis. There has always been a more or less explicit conflict between research-oriented scholars and some in the psychoanalytic community. The PDM-1 has been criticized with the argument that virtually any use of categorization in relation to patients is a desiccation of human experience (Hoffman, 2009). But we need a constructive way to bridge the gap between research and clinical work-a bridge that makes research more creative and ecologically valid and the clinician's challenge more grounded. We see this as the only way to make diagnosis meaningful (Eagle \& Wolitzky, 2011).

\section{Background to This Special Issue}

Once the PDM-2 was published, we decided to launch it with a conference organized by Ruth Helein, the Division 39 Administrator, and Eleonora Piacentini, from Sapienza University in Rome, and held in New York City in June 2017 at the New School for Social Research. To our surprise, the meeting sold out in the first 2 days it was advertised. It was a fine occasion to get together with researchers, psychiatrists, psychologists, psychotherapists, social workers, counselors, students, and teachers. This convention enabled members of the scientific community to confer, but, perhaps more important, it allowed participants to revive the dialogue around diagnosis among people working in different fields and coming from different approaches. Contributors and commentators gave talks and participated in group discussions. It was on that occasion that it occurred to us to ask the editors of Psychoanalytic Psychology whether they would be interest in our overseeing a special issue of the journal, dedicated entirely to the PDM-2, that would collect and develop many of the contributions presented at the conference. We are grateful to Elliot Jurist and Christopher Christian for granting our request.

In this special issue, by placing the complex idiographic understanding of a person back at center stage in the diagnostic process, our goal is to highlight what the PDM- 2 can add to the current panorama of clinical research and applied clinical knowledge. We begin with commentaries by both Kernberg (2018) and Frances (2018), who opened our launch conference in New York. Kernberg, who has defined the PDM-2 as "the most sophisticated presently available system we have for diagnosing individuals" (p. 294), focuses on its clinical importance; he discusses its contributions to the psychodynamically informed classification of both psychopathologies and the normal range of psychological organization as well its integration of multiple theoretical and clinical perspectives. Allen Frances discusses the PDM-2 in the context of its psychiatric history, especially the effects of certain recent trends on psychoanalytic understandings, observing that "the beauty of PDM-2 is its effort to add the texture and complexity that has been leveled away with the limited focus on surface symptoms" (p. 298). He also encouraged us to develop a pocketsized manual, a mini-PDM, that would be more user friendly than the tome the PDM turned out to be.

The first article, by McWilliams, Grenyer, and Shedler (2018), focuses on the Adult Personality section (P Axis), which aims to capture clinically relevant personality constellations, from healthy personality styles to highly troubled versions of personality organization. They describe and give the rationale for changes from PDM-1 to PDM-2 and call attention to ongoing controversies in the field of personality diagnosis, in particular those involving the concept of psychotic level of personality organization and diagnostic complexities and uncertainties surrounding depressive, masochistic (self-defeating), passive-aggressive, schizotypal, hypomanic, and anxious personality patterns.

The next contribution, by Lingiardi, Colli, and Muzi (2018), explicates the use of the M Axis for a deeper understanding of the therapeutic alliance. The authors assess some capacities delineated in the manual's M Axis because they pertain to both the patient's and the therapist's mental functioning. Using the Collaborative Interaction Scale-Revised (Colli, Gentile, Condino, \& Lingiardi, 2017) as a lens through which to view the dynamics of the therapeutic alliance (in particular, its rupture and repair), the authors illustrate how specific M Axis capacities can be examined via this instrument. The article concludes with the transcript of a section of a clinical session analyzed via the Collaborative Interaction Scale-Revised.

The third paper, by Mundo, Persano, and Moore (2018), addresses the main innovations of the PDM-2 S Axis, the conceptualization of adult symptom patterns as they are experienced subjectively by patients and, not incidentally, by therapists. The authors make useful comparisons between the ICD-10, DSM-5, and PDM-2.

The next contribution, by Hilsenroth, Katz, and Tanzilli (2018), considers applications of the PDM-2 to the field of psychotherapy research, with a special focus on issues of personality (P Axis) and mental functioning (M Axis).

Speranza, Malberg, and Steele (2018) then explicate mental health and developmental disorders in infancy and early childhood per their eponymous chapter in the PDM-2. They illustrate the interplay between the evolution of developmental theories and early diagnoses and clinical formulations. Their article includes an illustrative case of an infant first described by Ernst Kris (1962) in a longitudinal study, later discussed by Sally Provence (1983) and now evaluated via the Infancy and Early Childhood Model of the PDM-2.

The PDM-2 developmental framework is further illuminated by Malone, Piacentini, and Speranza (2018), who discuss diagnosis and clinical formulation relevant to the adolescent years. They include comprehensive assessments of two patients (one in early adolescence, one in late adolescence), following the PDM-2 approach to mental functioning (MA Axis), emerging personality patterns (PA Axis), and subjective experience of symptom patterns (SA Axis).

An approach to assessment of the elderly patient is perhaps the most innovative contribution of the revised PDM. Since conceiving this addition, we have learned that it is the first general psychodiagnostic system to include special attention to the interactions between aging and psychopathology. The PDM-2 perspective on later life is reviewed in the article by Del Corno and Kiosses (2018). The authors explore the complexities of such diagnostic assessment as it relates to mental functioning, personality patterns, and the evaluation of symptoms and their effects on the subjectivities of patients and clinicians.

Bornstein (2018) then examines how the PDM-2 can enhance case formulation, psychodynamic and otherwise. After describing the evolution of the major diagnostic systems, he discusses the role of diagnostic manuals in case formulation, emphasizing areas in which the PDM-2 may be more helpful than other taxonomies. 
Finally, he explains how the PDM-2 sets the stage for more rigorous multimethod psychological assessment that can enhance case conceptualization and facilitate treatment, and he makes suggestions for future work in this area.

Finally, Drescher and Fors (2018) present a case of a sexual minority patient treated by a sexual minority therapist. They use the clinical material to reflect on the benefits and limits of PDM2's new section, "Psychological Conditions That May Require Clinical Attention," an appendix to the S Axis that addresses clinically significant subjective experiences of nonpathological populations who may seek help because of minority stress, internalized prejudice, and conditions of social disadvantage or oppression.

Jurist (2018) provides the concluding paper, an editorial comment on the PDM and the contents of this issue.

\section{Tomorrow}

A few weeks after the PDM-2 was published, Guilford Publications informed us of the need for a second printing. We are rapidly moving toward needing a third. In addition to being personally gratifying, such an initial response seems like prima facie evidence that there is great interest in, and perhaps a demonstrated need for, the approach to diagnosis and case formulation that the PDM has tried to represent. We have now received enough royalties to set up a committee to evaluate applications for grants for research and training from the PDM coffers. This is our next task.

At the same time, we are seeing progress in acquainting the international community with the value of the manual. The Italian translation was published in March 2018. As of this writing, Guilford Publications has signed contracts for translations of PDM-2 into Chinese, Korean, Polish, Russian, and Turkish and is in negotiations about translations in Dutch, French, Japanese, Norwegian, Spanish, and Swedish.

We hope this special issue will provide readers with a more in-depth journey into the world of the PDM-2, showing how it might be used in both clinical and research contexts. As teachers and supervisors, we realize every day how many young colleagues feel lost in a biomedical diagnostic world and how keenly they feel the lack of a more psychologically articulated system. Without the dynamic, relational, and intersubjective aspects of diagnosis, the process stops making sense and risks becoming routinized and corrupted by interests that compete with the aim of understanding for clinical purposes. This situation not only puts stress on clinicians' professional identity but also dims or distorts our ability to detect and describe patients' clinically salient characteristics and mental functioning, a distortion that can jeopardize the therapeutic relationship.

The PDM has been a labor of love. Future editions will have to depend on the love of tomorrow's clinicians, scholars, researchers, and theorists for the complexity it represents and for its insistence on valuing the whole person. We are pleased the PDM- 2 has gotten off to a good start, and we are cheered by the fact that, via the manual's success, we can support relevant clinical education and we can underwrite future research that will, unlike many academic studies of short-term symptom reduction with only minimal clinical applicability to complex patients, be of genuine value to therapists.
In our opinion, a clinician engaged in a good diagnostic process (in terms of personality and mental functioning but also with respect to symptoms and/or problematic behaviors) is not like an entomologist who kills a butterfly to categorize it. Diagnosis is a dynamic process, in all senses. We hope we have captured that here.

\section{References}

Barthes, R. (1980). Camera Lucida. Reflections on photography. New York, NY: Hill and Wang.

Bornstein, R. (2018). From symptom to process: Case formulation, clinical utility, and PDM-2. Psychoanalytic Psychology, 35, 351-356. http://dx .doi.org/10.1037/pap0000191

Colli, A., Gentile, D., Condino, V., \& Lingiardi, V. (2017). Assessing alliance ruptures and resolutions: Reliability and validity of the Collaborative Interactions Scale-revised version. Psychotherapy Research. Advance online publication. http://dx.doi.org/10.1080/10503307.2017 .1414331

Del Corno, F., \& Kiosses, D. N. (2018). The PDM-2 perspective on later life. Psychoanalytic Psychology, 35, 346-350. http://dx.doi.org/10 $.1037 /$ pap0000190

Drescher, J., \& Fors, M. (2018). An appreciation and critique of PDM-2's focus on minority stress through the case of Frank. Psychoanalytic Psychology, 35, 357-362. http://dx.doi.org/10.1037/pap0000199

Eagle, M. N., \& Wolitzky, D. L. (2011). Systematic empirical research versus clinical case studies: A valid antagonism? Journal of the American Psychoanalytic Association, 59, 791-818. http://dx.doi.org/10 $.1177 / 0003065111416652$

Frances, A. (2018). Commentary on the Psychodynamic Diagnostic Manual, 2nd Edition: The PDM-2 as an effort to enhance the psychiatric diagnosis. Psychoanalytic Psychology, 35, 296-298. http://dx.doi.org/ 10.1037/pap0000189

Freud, S. (1933). New introductory lectures on psycho-analysis. Standard Edition, 22, 3-182.

Hilsenroth, M., Katz, M., \& Tanzilli, A. (2018). Psychotherapy research and the Psychodynamic Diagnostic Manual (PDM-2). Psychoanalytic Psychology, 35, 320-327. http://dx.doi.org/10.1037/pap0000207

Hoffman, I. Z. (2009). Doublethinking our way to "scientific" legitimacy: The desiccation of human experience. Journal of the American Psychoanalytic Association, 57, 1043-1069. http://dx.doi.org/10.1177/0003 065109343925

Jaspers, K. (1913). Allgemeine Psychopathologie [General Psychopathology]. Berlin, Germany: Springer-Verlag. (Tr. Eng. Johns Hopkins University Press, Reprint ed., November 1997).

Jurist, E. (2018). A concluding commentary on the special issue on the PDM-2: Celebration and future hopes (plus a few anxieties). Psychoanalytic Psychology, 35, 363-366. http://dx.doi.org/10.1037/pap0000202

Kernberg, O. F. (2018). Commentary on the Psychodynamic Diagnostic Manual, 2nd Edition: What does the PDM-2 add to the current diagnostic panorama? Psychoanalytic Psychology, 35, 294-295. http://dx .doi.org/10.1037/pap0000208

Kris, E. (1962). Decline and recovery in the life of a three-year-old. Psychoanalytic Study of the Child, 17, 175-215. http://dx.doi.org/10 .1080/00797308.1962.11822845

Lingiardi, V., Colli, A., \& Muzi, L. (2018). A clinically useful assessment of patients' (and therapists') mental functioning: M-Axis implications for the therapeutic alliance. Psychoanalytic Psychology, 35, 306-314. http://dx.doi.org/10.1037/pap0000200

Lingiardi, V., \& McWilliams, N. (2015). The Psychodynamic Diagnostic Manual - 2nd Edition (PDM-2). World Psychiatry, 14, 237-239. http:// dx.doi.org/10.1002/wps.20233

Malone, J. C., Piacentini, E., \& Speranza, M. (2018). Reclaiming the developmental lens for adolescent formulation and diagnosis: Applica- 
tion of the PDM-2 to clinical cases. Psychoanalytic Psychology, 35, 339-345. http://dx.doi.org/10.1037/pap0000194

McWilliams, N., Grenyer, B. F. S., \& Shedler, J. (2018). Personality in the PDM-2: Controversial issues. Psychoanalytic Psychology, 35, 299-305. http://dx.doi.org/10.1037/pap0000198

Mundo, E., Persano, H., \& Moore, K. (2018). The S axis in PDM-2. Symptom patterns: The subjective experience. Psychoanalytic Psychology, 35, 315-319. http://dx.doi.org/10.1037/pap0000195
Provence, S. (1983). Struggling against deprivation and trauma. A longitudinal case study. Psychoanalytic Study of the Child, 38, 233-256. http://dx.doi.org/10.1080/00797308.1983.11823391

Speranza, A. M., Malberg, N., \& Steele, M. (2018). Mental health and developmental disorders in infancy and early childhood: The PDM-2. Psychoanalytic Psychology, 35, 328-338. http://dx.doi.org/10.1037/pap0000192

Stepansky, P. E. (2009). Psychoanalysis at the margins. New York, NY: Other Press.

\section{(1) American Psycholooical Assocation APA JOURNALS ${ }^{\circledast}$}

\section{ORDER INFORMATION}

Start my 2018 subscription to

Psychoanalytic Psychology

ISSN: 0736-9735

\section{PRICING}

APA Member/Affiliate $\$ 79$

Individual Nonmember $\$ 146$

Institution $\$ 967$

Call 800-374-2721 or 202-336-5600

Fax 202-336-5568 | TDD/TTY 202-336-6123

Subscription orders must be prepaid. Subscriptions are on a calendar year basis. Please allow 4-6 weeks for delivery of the first issue.

Learn more and order online at: www.apa.org/pubs/journals/pap

\section{Visit www.apa.org/journals/circ18} to browse APA's full journal collection.

All APA journal subscriptions include online first journal articles and access to archives. Individuals can receive online access to all of APA's 90 scholarly journals through a subscription to APA PsycNET ${ }^{\circledR}$, or through an institutional subscription to the PsyCARTICLES ${ }^{\circledR}$ database.

To learn more, visit www.apa.org/db/circ18 